\title{
Partial corpus callosum agenesis- cerebellar vermis hypoplasia with posterior fossa cysts syndrome
}

INSERM

\section{Source}

INSERM. (1999). Orphanet: an online rare disease and orphan drug data base. Partial corpus callosum agenesis-cerebellar vermis hypoplasia with posterior fossa cysts syndrome. ORPHA:401959

Partial corpus callosum agenesis-cerebellar vermis hypoplasia with posterior fossa cysts syndrome is a rare, hereditary, cerebral malformation with epilepsy syndrome characterized by severe global developmental delay with no ability to walk and no verbal language, intractable epilepsy, partial agenesis of the corpus callosum and cerebellar vermis hypoplasia with posterior fossa cysts. 